\title{
Correction to: Transcriptional factor six2 promotes the competitive endogenous RNA network between CYP4Z1 and pseudogene CYP4Z2P responsible for maintaining the stemness of breast cancer cells
}

Lufeng Zheng ${ }^{1}$, Qianqian Guo ${ }^{1}$, Chenxi Xiang ${ }^{3}$, Shijia Liư ${ }^{4}$ Y Yuzhang Jiang ${ }^{5}$, Lanlan Gao ${ }^{1}$, Haiwei Ni ${ }^{1}$, Ting Wang ${ }^{1}$, Qiong Zhao', Hai Liu', Yingying Xing ${ }^{1}$, Yaohui Wang ${ }^{6}$, Xiaoman $\mathrm{Li}^{2^{*}}$ and Tao Xi ${ }^{*}$

Correction to: J Hematol Oncol (2019) 12:23

https://doi.org/10.1186/s13045-019-0697-6

The original article [1] contained an error in Fig. 7c whereby the same flow image was accidentally misused for the second and fourth group. The correct version of Fig. 7c can be viewed below together with the rest of Fig. 7 .

\begin{abstract}
Author details
${ }^{1}$ Jiangsu Key Laboratory of Carcinogenesis and Intervention, School of Life Science and Technology, China Pharmaceutical University, 24 Tong Jia Xiang, Nanjing 210009, China. ${ }^{2}$ Jiangsu Key Laboratory for Pharmacology and Safety Evaluation of Chinese Materia Medica, School of Pharmacy, Nanjing University of Chinese Medicine, Nanjing 210023, China. ${ }^{3}$ Department of Pathology, The Affiliated Hospital of Xuzhou Medical University, Xuzhou 221002, Jiangsu, China. ${ }^{4}$ Department of Pharmacy, Jiangsu Province Hospital of TCM, Nanjing 210023, China. ${ }^{5}$ Department of Clinical Laboratory, Huai An First People's Hospital, Huai An 223300, China. ${ }^{6}$ Department of Pathology, Jiangsu Province Hospital of TCM, Nanjing 210023, China.
\end{abstract}

Published online: 24 October 2019

\section{Reference}

1. Zheng L, Guo Q, Xiang C, Liu S, Jiang Y, Gao L, et al. Transcriptional factor six2 promotes the competitive endogenous RNA network between CYP4Z1 and pseudogene CYP4Z2P responsible for maintaining the stemness of breast cancer cells. J Hematol Oncol. 2019;12:23. https://doi.org/10.1186/ s13045-019-0697-6.

\footnotetext{
*Correspondence: xiaoman1205@163.com; xitao18@hotmail.com

${ }^{2}$ Jiangsu Key Laboratory for Pharmacology and Safety Evaluation of Chinese Materia Medica, School of Pharmacy, Nanjing University of Chinese Medicine, Nanjing 210023, China

${ }^{1}$ Jiangsu Key Laboratory of Carcinogenesis and Intervention, School of Life Science and Technology, China Pharmaceutical University, 24 Tong Jia Xiang, Nanjing 210009, China

Full list of author information is available at the end of the article
}

(c) The Author(s). 2019 Open Access This article is distributed under the terms of the Creative Commons Attribution 4.0 International License (http://creativecommons.org/licenses/by/4.0/), which permits unrestricted use, distribution, and reproduction in any medium, provided you give appropriate credit to the original author(s) and the source, provide a link to the Creative Commons license, and indicate if changes were made. The Creative Commons Public Domain Dedication waiver (http://creativecommons.org/publicdomain/zero/1.0/) applies to the data made available in this article, unless otherwise stated. 


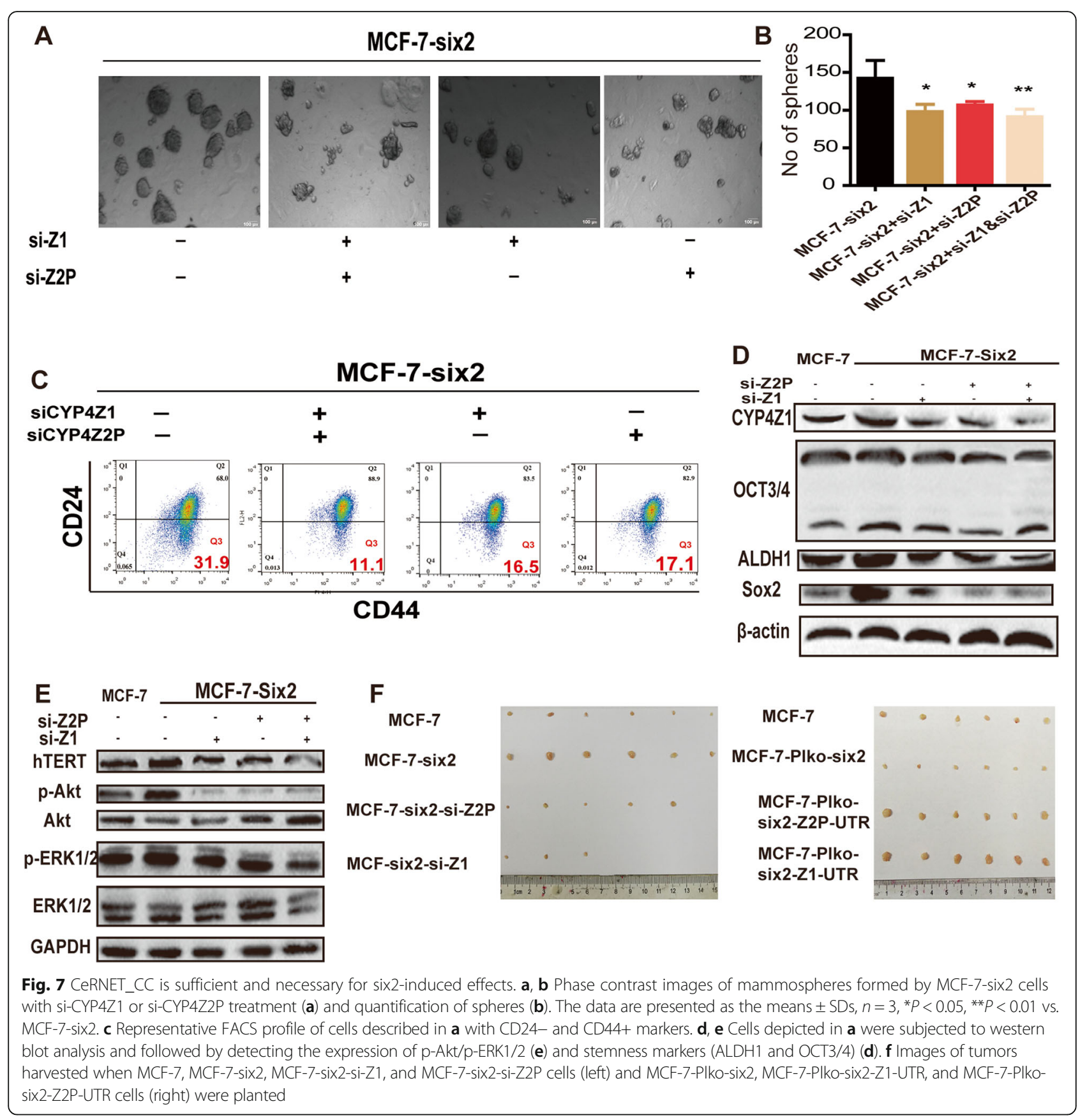

